\title{
Melatonin Secretion Inhibition
}

National Cancer Institute

\section{Source}

National Cancer Institute. Melatonin Secretion Inhibition. NCI Thesaurus. Code C41504.

Melatonin Secretion Inhibition consists of interference with, or restraint of, activities involved in release into the bloodstream from the pineal gland of a hormone (melatonin) implicated in regulation of sleep, mood, puberty, and ovarian cycles. 